Western University

Scholarship@Western

Obstetrics \& Gynaecology Publications

Obstetrics \& Gynaecology Department

Summer 7-19-2016

\title{
Effects of American Ginseng on Preimplantation Development and Pregnancy in Mice.
}

Danyka Belanger

Michele D Calder

Alessandra Gianetto-Berruti

Edmund M Lui

Andrew J Watson

See next page for additional authors

Follow this and additional works at: https://ir.lib.uwo.ca/obsgynpub

Part of the Obstetrics and Gynecology Commons

Citation of this paper:

Belanger, Danyka; Calder, Michele D; Gianetto-Berruti, Alessandra; Lui, Edmund M; Watson, Andrew J; and Feyles, Valter, "Effects of American Ginseng on Preimplantation Development and Pregnancy in Mice." (2016). Obstetrics \& Gynaecology Publications. 36.

https://ir.lib.uwo.ca/obsgynpub/36 
Authors

Danyka Belanger, Michele D Calder, Alessandra Gianetto-Berruti, Edmund M Lui, Andrew J Watson, and Valter Feyles 
For submission to the American Journal of Chinese Medicine-Revised manuscript

Effects of Ginseng extract treatment on preimplantation development in vitro and pregnancy in the mouse

Danyka Belanger ${ }^{1,2,3}$, Michele D Calder ${ }^{1,2,3}$, Alessandra Gianetto-Berruti ${ }^{1}$, Edmund M Lui $^{2}$, Andrew J Watson ${ }^{1,2,3}$,Valter Feyles ${ }^{1,3}$

Departments of ${ }^{1}$ Obstetrics and Gynaecology, and ${ }^{2}$ Physiology \& Pharmacology, The University of Western Ontario, ${ }^{3}$ Children's Health Research Institute- Lawson Health Research Institute, London, Ontario, Canada. N6A 5C1

Running Title: American Ginseng Extract in vitro and in vivo effects on mouse development

Number of pages, figures and tables: 23 pages; 5 figures; 1 table

Corresponding Author: Andrew J Watson, Departments of Obstetrics and Gynaecology and Physiology and Pharmacology, Rm 2708 Rix Clinical Skills Bldg, The University of Western Ontario, London Ontario Canada N6C 2V5; awatson@uwo.ca; tel: 519-661-2111 x89132; Fax: 519-661-3797. 


\section{Abstract:}

In North America a high proportion of pregnant women use herbal medications, including North American ginseng. This medicinal plant contains a high amount of triterpene saponins (ginsenosides) which are the main bioactive compounds. It is important to assess ginseng's impact on all reproductive functions to ensure the safety of pregnant women and fetuses. In this study, we defined the concentration responsive effects of North American alcoholic and aqueous ginseng extracts on preimplantation development in vitro and on pregnancy and post-partum development in the mouse. Two-cell mouse embryos were cultured with 5 different concentrations of whole ginseng root extracts, or ginsenosides $\mathrm{Rb} 1, \mathrm{Rg} 1$ and Re alone, a combinatorial ginsenoside solution and a crude polysaccharide fraction solution. Embryonic development and recovery from treatment was assessed. To investigate in vivo effects of ginseng extracts, female mice were gavaged with $50 \mathrm{mg} / \mathrm{kg} / \mathrm{day}, 500 \mathrm{mg} / \mathrm{kg} /$ day or $2000 \mathrm{mg} / \mathrm{kg} /$ day of either extract (treatment) or water (sham) for 2 weeks prior to mating and throughout gestation. Gestation period, litter size, pup growth and pup sex ratio were evaluated. Oral ginseng consumption did not significantly affect fertility or pregnancy in the mouse. High doses of ginseng $(2000 \mathrm{mg} / \mathrm{kg} /$ day) decreased maternal weight gain. Direct treatment of preimplantation embryos in vitro demonstrated that ALC and AQ extract treatment reduced development in a concentration responsive manner, while only ALC extract effects were largely reversible. Treatments with individual or combinatorial ginsenosides or polysaccharide fraction solution alone did not impair preimplantation development, in vitro. In conclusion, maternal oral consumption of ginseng has little negative impact on pregnancy in the mouse 
however direct exposure to ginseng extract during mouse preimplantation development in vitro is detrimental.

Key Words: ginseng, ginsenosides, fertility, blastocyst, pregnancy, assisted reproductive technologies 


\section{Introduction:}

Ginseng is one of the ten most commonly used herbal medicines in the United States (Bent and Ko, 2004; Chu and Zhang, 2009). Ginseng extracts have reported benefits to the cardiovascular, nervous and the reproductive systems (Attele et al., 1999). In the US, 9-45\% of pregnant women use herbal supplements during pregnancy (Eisenberg et al., 1998; Gibson et al., 2001; Tsui et al., 2001; Glover et al., 2003), with 2.4\% ingesting ginseng (Glover et al., 2003). Use of herbal products varies from 26-40\% of European women during pregnancy (Bishop et al., 2011; Nordeng et al., 2011). In China, up to 15\% of women consume ginseng during pregnancy, as it is believed to be "good for pregnancy and the fetus" (Ong et al., 2005). Herbal remedies are often deemed harmless because they are "natural", but this does not in any way ensure that consumption of ginseng is safe for preimplantation development or pregnancy (De Smet et al., 2004). Most herbal products carry a warning label to not consume during pregnancy. This is related to the lack of scientific information on safety during pregnancy. Approximately 40 ginsenoside compounds have been identified from the ginseng root (Fuzzati, 2004). Ginsenosides belong to a family of steroids called triterpene saponins (Attele et al., 1999) and are either derivatives of the (20S)-protopanaxadiols (PD), (20S)-protopanaxatriols (PT, Tawab et al., 2003), acotillol-type or oleanolic acid groups (Fuzzati, 2004). The other major component found in water extract is polysaccharides, which are sugar polymers that have immunemodulatory activity.

To date, research investigating ginseng's impact on reproductive function has demonstrated lower morphological scores for in vitro treated rat and mouse postimplantation embryos than for control embryos (Chan et al., 2003, 2004; Liu et al., 2005, 
2006). Conversely, Lee et al. (2008) found treatment of early rat embryos with individual ginsenosides resulted in either no significant change to the morphological scores or improvements. In addition, very recent in vivo studies have shown that when up to 2000 $\mathrm{mg} / \mathrm{kg} /$ day $(\approx 200$ times the recommended clinical dose) of Korean Red Ginseng extract was administered to female mice, maternal weight, feeding, embryonic implantation and fetal growth were not significantly affected (Shin et al., 2010).

It is important to establish whether consumption of ginseng extracts are safe during pregnancy and what effects, if any, direct exposure to these extracts may have on preimplantation development. North American ginseng (NAG) has a much higher concentration of ginsenosides Rb1 and Re, and little Rf compared to Asian ginseng extract (Kitts et al., 2000; Sievenpiper et al., 2004; Sun et al., 2011). Furthermore, the alcoholic (ALC) extract derived from NAG possesses twice the total concentration of ginsenosides as the Aqueous (AQ) extract, specifically $282.5 \mathrm{mg} / \mathrm{g}$ versus $138.7 \mathrm{mg} / \mathrm{g}$ (Azike et al., 2011). In addition, the AQ extract is composed of $15 \%$ polysaccharides, whereas the ALC extract has none. Finally, due to so much variability between the compounds found in different ginseng products (Liberti and Der Marderosian, 1978), it is important to study the effects of different ginseng species and extracts on reproduction, which is why the aqueous and alcoholic extracts produced from NAG are the focus of this research.

\section{Materials and Methods}

\section{Chemicals}

KSOMaa (potassium simplex optimized medium with amino acids) was used for embryo culture medium (EMD Millipore Corporation, Billerica, MA, USA). The Ontario Ginseng 
Growers Association provided four-year-old North American ginseng roots, which were extracted to produce the AQ and ALC fractions (Azike et al., 2011). The crude polysaccharide preparation was obtained after precipitation from AQ extract in the presence of $40 \%$ alcohol (Azike et al., 2011). Ginsenosides Rb1, $\operatorname{Rg} 1$ and Re were purchased from Sigma (St. Louis, MO. USA).

\section{Animals}

All animal care and handling procedures were conducted as approved by the University of Western Ontario, Animal Care and Veterinary Science (ACVS), standard operating procedures that conform to guidelines produced by the Canadian Council for Animal Care (CCAC). Six-eight week old female MF1 mice were purchased from Harlan Laboratories (Indiana, USA) and CD1 mice were purchased from Charles River (Canada). Each female was injected with 7.5 units of Pregnant mares serum gonadotrophin (Folligon, Intervet, Whitby, ON), then 7.5 units of human chorionic gonadotrophin (Chorulon, Intervet) $48 \mathrm{~h}$ later and placed with CD1 males for mating. Pregnancy was confirmed the following morning by the presence of a vaginal plug which was considered gestational day one. On gestational day two, the mice were euthanized employing $\mathrm{CO}_{2}$ asphyxiation, followed by cervical dislocation. Oviducts were dissected and two-cell stage embryos were flushed with M2 flushing medium (Sigma, St. Louis, MO, USA). For all in vitro treatment experiments, 20 embryos were cultured in $20 \mu \mathrm{l}$ drops under oil at $37^{\circ} \mathrm{C}$ under a $5 \% \mathrm{O}_{2}, 5 \% \mathrm{CO}_{2}$ and $90 \% \mathrm{~N}_{2}$ atmosphere for $48 \mathrm{~h}$. 


\section{In vitro Experimental Sequence}

\section{Alcohol and Aqueous Ginseng Extracts}

Two-cell embryos were washed three times in KSOMaa. Individual stock solutions $(10,000$ $\mu \mathrm{g} / \mathrm{ml}$ ) of the alcoholic and aqueous ginseng extracts were made in KSOMaa. These stock solutions were diluted to prepare: 0 (control), 10, 50, 250 and $1000 \mu \mathrm{g} / \mathrm{ml}$ of each extract.

\section{Individual Ginsenoside Rb1, Rg1 and, Re Treatments}

Ginsenoside concentrations were calculated to equal the highest actual individual concentrations in either of the AQ and ALC extracts. One mg of ginsenoside Rb1, Rg1 and Re were individually mixed with $1 \mathrm{~mL} \mathrm{KSOMaa} \mathrm{to} \mathrm{prepare} 1000 \mu \mathrm{g} / \mathrm{ml}$ stock solutions. The stock solutions were then diluted for each individual ginsenoside as follows: Rb1 164.5, 41.1, 8.2, 1.6 and $0 \mu \mathrm{g} / \mathrm{ml} ; \operatorname{Rg} 1$ 13.1, 2.6, 0.66, 0.15 and $0 \mu \mathrm{g} / \mathrm{ml}$ and $\operatorname{Re} 89.6,22.4$, $4.5,0.9$ and $0 \mu \mathrm{g} / \mathrm{ml}$.

\section{Ginsenoside Combinatorial Experiments}

Two-cell embryos were washed three times in KSOMaa. Ginsenoside concentrations were calculated to equal the actual individual concentrations of $\mathrm{Rb} 1, \operatorname{Rg} 1$ and $\operatorname{Re}$ found in the ALC extract. Three individual stock solutions $(1000 \mu \mathrm{g} / \mathrm{ml})$ of purified ginsenoside $\mathrm{Rb} 1$, Rg1 and Re were made. The stock solutions were diluted to equal the $257.1 \mu \mathrm{g} / \mathrm{ml}$ concentration found in $1000 \mu \mathrm{g} / \mathrm{ml}$ of the alcoholic extract: which consisted of $\mathrm{Rb} 1(64 \%)$; $\operatorname{Rg} 1(1 \%)$ and $\operatorname{Re}(35 \%)$. This stock was then diluted to provide the five treatment concentrations of $257.1,64.3,12.9,2.6$ and $0 \mu \mathrm{g} / \mathrm{ml}$. 


\section{Polysaccharide Fraction}

For all polysaccharide fraction (PSF) experiments, CD1 females were used. Fifteen percent of the aqueous extract is composed of PSF, thus this percentage was used to calculate the maximum concentration in $1000 \mu \mathrm{g} / \mathrm{ml} \mathrm{AQ} \mathrm{extract.} \mathrm{A} \mathrm{stock} \mathrm{solution} \mathrm{of} 10,000$ $\mu \mathrm{g} / \mathrm{ml}$ PSF was made and then this stock solution was adjusted to the following concentrations: $150,37.5,7.5,1.5$ and $0 \mu \mathrm{g} / \mathrm{ml}$.

\section{Morphological Assessment}

For all in vitro experiments, embryo development was assessed after $48 \mathrm{~h}$ of treatment. After treatment and culture, the cell number of each embryo was determined and categorized into 2, 4 or 8 cells, 8-cell compacted, morula or blastocyst groups.

\section{Recovery from Treatment}

After the morphological assessment following $48 \mathrm{~h}$ of treatment, embryos in all experiments were washed three times in fresh ginseng or ginsenoside free KSOMaa and returned to culture for another $72 \mathrm{~h}$ in order to determine if recovery from ginseng exposure was possible. After 24 and $72 \mathrm{~h}$, embryos were once again categorized into their specific developmental stages.

\section{In vivo experiments}

\section{Animals}

In the first two experiments, female MF1 mice (six-eight weeks old) were gavaged for 14 days prior to mating and throughout gestation. For the third experiment, CD1 females were 
used, as MF1 mice were no longer commercially available. Three experiments were conducted, females gavaged $50 \mathrm{mg} / \mathrm{kg} /$ day (MF1), females gavaged $500 \mathrm{mg} / \mathrm{kg} / \mathrm{day}$ (MF1), and females gavaged $2000 \mathrm{mg} / \mathrm{kg} /$ day (CD1) for 14 days prior to mating and throughout gestation. The experiments consisted of three treatment groups: sham-gavaged water, aqueous extract and alcoholic extract. When administering a dose of 500 or 2000 $\mathrm{mg} / \mathrm{kg} / \mathrm{day}$, the solutions were prepared 10 or 40 times more concentrated than the 50 $\mathrm{mg} / \mathrm{kg} / \mathrm{day}$ concentration to keep volumes gavaged to a maximum of $0.3 \mathrm{ml}$ total volume/day. Females were gavaged (using standard operating procedures as outlined by Western University's ACVS) once per day for 14 days prior to natural mating and during gestation. The volume gavaged was calculated according to individual mouse weights and adjusted as the mouse gained weight during pregnancy. Females were naturally mated by placing with CD1 males for up to five days. Following detection of a vaginal plug, females were separated from males and placed into individual cages until they gave birth. $\mathrm{N}$ values were 4-6 pregnant mice per treatment group per experiment.

\section{Outcome Assessment}

Once litters were born, day of birth, litter size, and gestation period were determined for each group in each experiment. Pups were individually weighed every four days until weaning on post-partum day 20 . Offspring sex was determined at weaning.

\section{Statistical Analysis}

Statistical analyses were done with GraphPad Prism version 4.0c software or SigmaStat 3.5 (Jandel Scientific, San Jose, CA). Each culture experiment was repeated a minimum of 
three times using embryos collected from replicate groups of mice. Data are presented as the mean \pm standard deviation (SD). For in vivo experiments, litter size, gestation period and proportion of male pups, statistical analyses were conducted with ANOVA. Where the conditions of normality or equal variance were not met, the Kruskal-Wallis non-parametric test on ranks was used. To correct for litter size, the mean pup or male/female pup weight was used for each litter in the analysis. We report on the results of one-way ANOVA for weights on the day of birth and at weaning. A two-way ANOVA analysis was used to examine the effects of treatment and sex on pup weight at weaning (D20). For maternal weights in the $2000 \mathrm{mg} / \mathrm{kg} /$ day experiment, during group housing in the feeding period before pregnancy, one-way ANOVA was used to detect treatment differences. During lactation, two-way ANOVA with repeated measures was used to evaluate maternal weights, multiple comparisons performed when effects were significant, $\mathrm{n}$ values were 56. Data were subjected to a reciprocal transformation $p<0.05$ was considered to be statistically significant.

\section{$\underline{\text { Results }}$}

\section{Effect of Aqueous Ginseng Extract Treatment on Mouse Preimplantation Development in vitro.}

Aqueous ginseng extract treatment resulted in a concentration-dependent inhibition of preimplantation development (Figure 1A). As the concentration of AQ extract increased, the number of embryos developing to the morula and blastocyst stages was significantly reduced $(p<0.05)$. Development was increasingly blocked at the two-cell and four-cell stages (Figure 1A). At $1000 \mu \mathrm{g} / \mathrm{ml}$, only $1.5 \%$ of embryos developed to the morula stage, 
whereas $71.7 \%$ of control embryos progressed to the morula stage after 48 hours of culture. Embryos treated with $10 \mu \mathrm{g} / \mathrm{ml}$ of the aqueous extract displayed the greatest recovery from treatment as blastocyst formation increased to nearly $80 \%$ blastocysts after $72 \mathrm{~h}$ of recovery time (Figure 1B). Exposure to all higher aqueous concentrations resulted in no development to the blastocyst stage at $48 \mathrm{~h}$ of culture $(p<0.05)$ and very limited recovery compared with the control (Figure 1B).

\section{Effect of Alcoholic Ginseng Extract Treatment on Mouse Preimplantation Development in vitro.}

Treatment with the alcoholic extract resulted in similar outcomes as that of the aqueous fraction, with concentrations of 50 and $250 \mu \mathrm{g} / \mathrm{ml}$ significantly $(p<0.05)$ increasing the numbers of embryos blocked in development at the two-cell stage (Figure 2A). Paradoxically, treatment with $1000 \mu \mathrm{g} / \mathrm{ml}$ did not result in developmental arrest (Figure 2A). All doses however resulted in decreased blastocyst development at $48 \mathrm{~h}$ of culture $(p<0.05)$. Embryos treated with 10,50 and $1000 \mu \mathrm{g} / \mathrm{ml}$ of ALC extract recovered from treatment by displaying no significant difference in blastocyst formation after 72 hour recovery period (Figure 2B). Interestingly, the developmental blockade resulting from treatment with $250 \mu \mathrm{g} / \mathrm{ml}$ ALC extract was only marginally reversed with $29.4 \%$ of treated embryos developing to the blastocyst stage, as opposed to $97.1 \%$ for control after $72 \mathrm{~h}$ of recovery time (Figure $2 \mathrm{~B})$. 


\section{Effect of Individual and Combinatorial Ginsenosides Rb1, Rg1, Re and}

Polysaccharide (PSF) Fraction Treatment on Mouse Preimplantation Development in vitro.

Experimentation using the highest Rb1 concentration found in our extracts resulted in a significant decrease $(p<0.05)$ in development to the morula stage between the control and $8.2 \mu \mathrm{g} / \mathrm{ml}$ of Rb1 (Figure 3A). However, following washing and recovery period, there were no differences in blastocyst development at $24 \mathrm{~h}$ and $72 \mathrm{~h}$ (Figure 3B). Embryos exposed to even the highest $\operatorname{Rg} 1$ concentrations found in our extracts progressed normally to the blastocyst stage (Figures 4A, B). In experiments conducted with ginsenoside concentrations of Re found in our preparations, no significant variations in embryo development between the control and treatment groups were observed (data not shown). Likewise experiments using combinatorial ginsenoside concentrations resulted in no significant impairment in development to the blastocyst stage (data not shown). Finally we treated two-cell stage embryos with polysaccharide fraction concentrations up to that found in the AQ fraction and also did not observe any significant impairment of development to the blastocyst stage (data not shown).

\section{Effects of oral consumption of either Ginseng Extract on Pregnancy and Post-Partum Development in the Mouse}

\section{Females Gavaged with 50 and 500 mg/kg/day Ginseng Extracts}

Parturition was checked twice daily (day of copulation plug = D1), the gestation period and litter size were determined (Table 1). No significant differences were observed 
between treatment groups for litter size or sex ratio in any of the gavage treatments (Table 1). Pup weights were determined by weighing 247 individual pups ( $50 \mathrm{mg} / \mathrm{kg} /$ day) and 212 pups $(500 \mathrm{mg} / \mathrm{kg} /$ day). There were no sex-specific pup weight differences at weaning due to treatment (data not shown).

\section{Females Gavaged with 2000 mg/kg Ginseng Extracts}

Weight of the females were not significantly different at the start of the treatment (Figure 5A), but after one week the ginseng groups weighed less than the SHAM group $(p<0.05$, Figure $5 \mathrm{~A})$. Ginseng treated females maintained this difference throughout the feeding period. For individual pregnancy (Figure 5A) days, there were significant effects due to treatment, all $p<0.05$. By the last gestational day SHAM animals weighed $7-8 \mathrm{~g}$ more than the ginseng treated females (Figure 5B). For repeated lactation weights (Figure 5B), there were significant differences due to treatment $(p<0.01)$ and days $(p<0.01)$. During lactation, The AQ extract group weighed less than the SHAM animals (Figure 5B). The average number of pups per litter on the day of birth did not vary significantly between treatment groups (Table 1). To evaluate pup growth and development, 173 pups were individually weighed every four days to Day 20 . Sex ratio of the pups did not differ among groups (Table 1).

\section{$\underline{\text { Discussion }}$}

There is a need to investigate the safety of North American ginseng consumption on preimplantation development, pregnancy and post-partum development as assessed in this study. We have discovered that AQ and ALC North American ginseng extract 
treatments caused a concentration dependent inhibition of development when applied directly to preimplantation embryos in culture, with the AQ extract causing more permanent effects. Exposure to individual ginsenosides, Rb1 and Rg1, did not produce lasting effects in vitro. Importantly, however, pregnancy was unaffected with orally administered NAG extracts up to $2000 \mathrm{mg} / \mathrm{kg} /$ day. This study indicates that direct exposure to ginseng extracts is detrimental to the completion of preimplantation development.

The effect of ginseng and ginsenosides on postimplantation embryos has been examined (Chan et al., 2003, 2004; Liu et al., 2005, 2006; Lee et al., 2008), however, few studies have investigated the direct influence on preimplantation embryo development.

Our in vitro study shows differences between treatments with the two types of extracts. Excluding embryos treated with the $250 \mu \mathrm{g} / \mathrm{ml}$ dose, all other groups treated with the ALC extract recovered from treatment and progressed onto the blastocyst stage after recovery, in contrast to the irreversibly decreased development in embryos treated with higher doses $(>50 \mu \mathrm{g} / \mathrm{ml})$ of the AQ extract. This difference is likely not simply due to total ginsenoside concentrations, as on a per weight basis ALC $>A Q$, but due to a varying compositions of ginsenoside or non-ginsenoside compounds.

In conclusion, the detrimental effect observed on embryonic development induced by treatment with the AQ and ALC ginseng extracts is concentration dependent, and direct embryo exposure to ginseng extracts is embryotoxic. Furthermore, once removed from treatment, embryo recovery is limited for AQ extract treatments greater than $10 \mu \mathrm{g} / \mathrm{ml}$ as most embryos in AQ treatments did not resume development if arrested at the two-cell and four-cell stages. In contrast, embryos treated with ALC extracts displayed a greater recovery from treatment than did the AQ treated embryos. We observed that the ALC 
extract displayed a concentration specific increase in the blockade of development at the 2-cell stage up to $250 \mu \mathrm{g} / \mathrm{ml}$. This concentration dependent effect however did not occur at the highest dose used $(1000 \mu \mathrm{g} / \mathrm{ml})$. This outcome is puzzling, but the effect is reminiscent of high ligand concentration effects on receptor desensitization and thus ligand/receptor signaling. Our study in no way defines the active component in the extract that is facilitating this outcome. We simply speculate that the higher dose induced reduction in 2cell developmental blockade allowed greater numbers of embryos to progress to the blastocyst stage and fully recover from treatment. Clearly there are some important differences in outcomes observed between direct treatment of early mouse embryos with $\mathrm{AQ}$ and $\mathrm{ALC}$ extracts in vitro.

In our study, we used the maximal $\operatorname{Rg} 1$ and $\mathrm{Rb} 1$ concentrations found in our extracts, but blastocyst rates were similar for all doses compared to the control. Liu et al., 2006 found that $\mathrm{Rg} 1$ remarkably decreased the total morphological score of postimplantation mouse and rat embryos when concentrations of 30 and $50 \mu \mathrm{g} / \mathrm{ml}$ were tested. Future studies investigating the effects of $\mathrm{Rg} 1$ on early development should consider the use of higher concentration treatments. Re is the second most prominent ginsenoside found in NAG extracts and is representative of the PT group. Re exerts a strong postimplantation embryotoxic effect starting with concentrations of $50 \mu \mathrm{g} / \mathrm{ml}$ (Chan et al., 2004). By contrast, our experiments displayed no significant delays in preimplantation embryonic development in vitro between the control and concentrations up to $89.6 \mu \mathrm{g} / \mathrm{ml}$ Re. Thus the overall conclusion from the single agent and combinatorial treatment experiments or PSF tested is that none negatively affected mouse preimplantation development. Thus the impact on preimplantation development observed from AQ and ALC treatment must either 
result from an individual component not yet identified, or the collective effects of several of the ginseng extract components adversely affecting early embryo development. Our results are the first to indicate that direct exposure to ginseng extracts is detrimental to preimplantation development.

These negative in vitro outcomes with whole extracts contrast the findings from in vivo studies investigating the influence of Red Korean Ginseng treatment two weeks before mating and throughout gestation on pregnancy in the mouse (Shin et al., 2010). Due to these discrepancies in outcomes it was essential to conduct in vivo experiments using NAG on pregnancy and post-partum development in the mouse. In this study doses of 50 $\mathrm{mg} / \mathrm{kg} /$ day to an extremely high dose of $2000 \mathrm{mg} / \mathrm{kg} /$ day NAG $\approx 200$ times the recommended daily dose of $1-2 \mathrm{~g}$ ) were investigated. Even at this dose, we observed no significant differences in the gestation period, litter size and sex ratio of mice weaned on post-partum day 20 . Females lost weight during the feeding period and gained significantly less weight during pregnancy, remaining lower through much of lactation, especially in the aqueous group, which may suggest a toxicity or satiety issue. Ginseng preparations may decrease post-meal blood glucose (Sievenpiper et al., 2004; Dascalu et al., 2007) or decrease gut uptake of sugars (Onomura et al., 1999). Most recommended levels for ginseng product consumption range from 1-2 g per day, indicating that a $50 \mathrm{~kg}$ woman would have to ingest $100 \mathrm{~g}$ of ginseng daily to equal the $2000 \mathrm{mg} / \mathrm{kg} / \mathrm{day}$ level that we investigated. The $50 \mathrm{mg} / \mathrm{kg} /$ day dose is much closer to realistic consumption levels.

We are intrigued by the fact that our in vivo results contrasted dramatically with the direct effects of NAG on preimplantation embryos. We believe this may be due to the fact that the concentrations of ginseng directly affecting embryos in vivo are unknown due to 
uncertainties regarding ginseng compound absorption, metabolism and renal clearance rate after consumption in the human. In light of the high water solubility of ginsenosides, and their low oral bioavailability, it is very likely that oral consumption results in very little embryonic exposure to ginseng compounds due to the low trans-placental transfer.

Overall our results support a cautionary approach to determining whether ginseng extract consumption has a negative influence on pregnancy and post-partum development.

\section{Acknowledgements}

This research was supported by the OGIRC program grant to Dr. Ed Lui and Dr. Valter Feyles. Ms. Belanger was supported by a training program grant from the CIHR Training Program in Reproduction, Early Development, and the Impact on Health (REDIH). 


\section{References}

Attele, A.S., J.A. Wu, and C.S. Yuan. Ginseng Pharmacology: multiple constituents and multiple actions. Biochem. Pharmacol. 58: 1685-1693, 1999.

Azike, C.G., P.A. Charpentier, J. Hou, H. Pei, E.M. King Lui. The Yin and Yang actions of North American ginseng root in modulating the immune function of macrophages.

Chin. Med. 6: 21, 2011.

Bent, S., and R. Ko. Commonly used herbal medicines in the United States: a review. Amer. J Med. 116: 478-485, 2004.

Bishop, J.L., K. Northstone, J.R. Green, and E.A. Thompson. The use of complementary and alternative Medicine in pregnancy: data from the Avon Longitudinal Study of Parents and Children (ALSPAC). Complement Ther. Med. 19: 303-310, 2011.

Chan, L.Y., P.Y. Chiu, and T.K. Lau. An in-vitro study of ginsenoside Rb1-induced teratogenicity using a whole rat embryo culture model. Hum. Reprod. 18: 2166-2168, 2003.

Chan, L.Y., P.Y. Chiu, and T.K. Lau. Embryotoxicity study of ginsenoside Rc and Re in in vitro rat whole embryo culture. Reprod. Toxicol. 19:131-134, 2004.

Chu, S.F., and J.T. Zhang. New achievements in ginseng research and its future prospects. Chin. J. Integr. Med. 15: 403-408, 2009.

Dascalu, A., J.L. Sievenpiper, A.L. Jenkins, M.P. Stavro, L.A. Leiter, J.T. Arnason, and V. Vuksan. Five batches representative of Ontario-grown American ginseng root produce comparable reductions of postprandial glycemia in healthy individuals. Can. J. Physiol. Pharmacol. 85:856-864, 2007. 
De Smet, P.A. Health risks of herbal remedies: an update. Clinical Pharmacol. Ther. 76: $1-7,2004$.

Eisenberg, D.M., R.B. Davis,S.L. Ettner, S. Appel, S. Wilkey, M. Van Rompay, and R.C. Kessler. Trends in alternative medicine use in the United States, 1990-1997: results of a follow-up national study. JAMA. 280: 1569 - 1575, 1998.

Fuzzati, N. Analysis methods of ginsenosides. J. Chromatogr. B. Analyt. Technol. Biomed. Life Sci. 812: 119-133, 2004.

Gibson, P.S., R. Powrie, and J. Star. Herbal and alternative medicine use during pregnancy: a cross sectional survey. Obstet. Gynecol. 97: S44-45, 2001.

Glover, D.D., M. Amonkar, B.F. Rybeck, and T.S. Tracy. Prescription, over-thecounter, and herbal medicine use in a rural, obstetric population. Am. J. Obstet. Gynecol. 188: 1039-1045, 2003.

Kitts, D.D., A.N. Wijewickreme, and C. Hu. Antioxidant properties of a North American ginseng extract. Mol. Cell Biochem. 203:1-10, 2000.

Lee, S.R., M.R. Kim, J.M. Yon, I.J. Baek, B.J. Lee, B. Ahn, Y.B. Kim, S.J. Kwack, R.D. Lee, S.S. Kim, D.H. Cho, G.H. Hur, Y.W. Yun, and S.Y. Nam. Effects of ginsenosides on organogenesis and expression of glutathione peroxidase genes in cultured rat embryos. J. Reprod. Dev. 54: 164-170, 2008.

Liberti, L.E., and A. Der Marderosian. Evaluation of commercial ginseng products. $J$. Pharm. Sci. 67: 1487-1489, 1978.

Liu. P., Y. Xu, H. Yin, J. Wang, K. Chen, and Y.Li. Developmental toxicity research of ginsenoside Rb1 using a whole mouse embryo culture model. Birth Defects Res. B. Dev. Reprod. Toxicol. 74: 207-209, 2005. 
Liu, P., H. Yin, Y. Xu, Z. Zhang, K. Chen, and Y.Li. Effects of ginsenoside Rg1 on postimplantation rat and mouse embryos cultured in vitro. Toxicol. In Vitro 20: 234-238, 2006.Nordeng, H., K. Bayne, G.C. Havnen, and B.S. Paulsen. Use of herbal drugs during pregnancy among 600 Norwegian women in relation to concurrent use of conventional drugs and pregnancy outcome. Complement Ther. Clin. Pract. 17: 147-151, 2011.

Ong, C.O., L.Y. Chan, P.B. Yung, and T.N. Leung. Use of traditional Chinese herbal medicine during pregnancy: a prospective survey. Acta. Obstet. Gynecol. Scand. 84: 699$700,2005$.

Onomura, M., H. Tsukada, K. Fukuda,M. Hosokawa, H. Nakamura, M. Kodama, M. Ohya, and Y. Seino. Effects of ginseng radix on sugar absorption in the small intestine. Am. J. Chin. Med. 27:347-354, 1999.

Shin, S., J.Y. Jang, D. Park, J.M. Yon, I.J. Baek, B.Y. Hwang, S.Y. Nam, Y.W. Yun, K.Y. Kim, S.S. Joo, and Y.B. Kim. Korean red ginseng extract does not cause embryofetal death or abnormalities in mice. Birth Defects Research B. Dev. Reprod. Toxicol. 89: 78-85, 2010.

Sievenpiper, J.L., J.T. Arnason, L.A. Leiter, and V. Vuksan. Decreasing, null and increasing effects of eight popular types of ginseng on acute postprandial glycemic indices in healthy humans: the role of ginsenosides. J. Am. Coll. Nutr. 23:248-258, 2004. Sun, S., L-W. Qi, G-J. Du, S.R. Mehendale, C-Z. Wang, and C-S. Yuan. Red notoginseng: higher ginsenoside content and stronger anticancer potential than Asian and American ginseng. Food Chem. 125: 1299-1305, 2011. 
Tawab, M.A., U. Bahr, M. Wurglics, and M. Schubert-Zsilavecz. Degradation of ginsenosides in humans after oral administration. Drug Metab. Dispos. 31: 1065-1071, 2003.

Tsui, B., C.E. Dennehy, and C.A. Tsourounis. Survey of dietary supplement use during pregnancy at an academic center. Am. J. Obstet. Gynecol. 185: 433-437, 2001. 


\section{Figure Descriptions:}

Figure 1: Development of 2-cell mouse embryos after $48 \mathrm{~h}$ treatment with aqueous extract. 2-cell embryos were flushed from the oviduct and placed into culture with 0$1000 \mu \mathrm{g} / \mathrm{ml}$ aqueous extract for $48 \mathrm{~h}$ (A) and up to $72 \mathrm{~h}$ recovery (B). Data are presented as the mean $\pm \mathrm{SD}$, representative of three independent replicates. Significant differences are represented by different superscripts $(p \leq 0.05)$.

Figure 2: Development of 2-cell mouse embryos after $48 \mathrm{~h}$ treatment with alcoholic extract. 2-cell embryos were flushed from the oviduct and placed into culture with 0$1000 \mu \mathrm{g} / \mathrm{ml}$ alcoholic extract for $48 \mathrm{~h}$ (A) and up to $72 \mathrm{~h}$ recovery (B). Data are presented as the mean $\pm \mathrm{SD}$, representative of three independent replicates. Significant differences are represented by different superscripts $(p \leq 0.05)$.

\section{Figure 3: Development and recovery of 2-cell mouse embryos treated with}

ginsenoside Rb1. 2-cell embryos were flushed from the oviduct and placed into culture with $0-164.5 \mu \mathrm{g} / \mathrm{ml} \mathrm{Rb1}$ for $48 \mathrm{~h}$ (A) and up to $72 \mathrm{~h}$ recovery (B). Data are presented as the mean $\pm \mathrm{SD}$, representative of three independent replicates. Significant differences are represented by different superscripts $(p \leq 0.05)$.

\section{Figure 4: Development and recovery of mouse embryos following treatment with} ginsenoside Rg1. 2-cell embryos were flushed from the oviduct and placed into culture with $0-13.1 \mu \mathrm{g} / \mathrm{ml} \mathrm{Rb1}$ for $48 \mathrm{~h}(\mathbf{A})$ and up to $72 \mathrm{~h}$ recovery (B). Data are presented as the 
mean \pm SD, representative of three independent replicates. Significant differences are represented by different superscripts $(p \leq 0.05)$.

Figure 5: Effect of ginseng treatment $(2000 \mathrm{mg} / \mathrm{kg} / \mathrm{day})$ on weight during the prebreeding, pregnancy and post-partum periods. Female mice were gavaged with water (SHAM) or $2000 \mathrm{mg} / \mathrm{kg} /$ day of either AQ or ALC ginseng extract for 2 weeks prior to mating and throughout gestation. Weight gain is reported during pre-breeding (A), gestation (B) and lactation periods (B). Differences in weight between treatment groups are presented as the mean $\pm \mathrm{SD}$, representative of 5-6 independent replicates. Significant differences between the SHAM control and ginseng treatments are represented by different superscripts $(p \leq 0.05)$. 
Figure 1

A $48 \mathrm{~h}$ treatment with aqueous extract

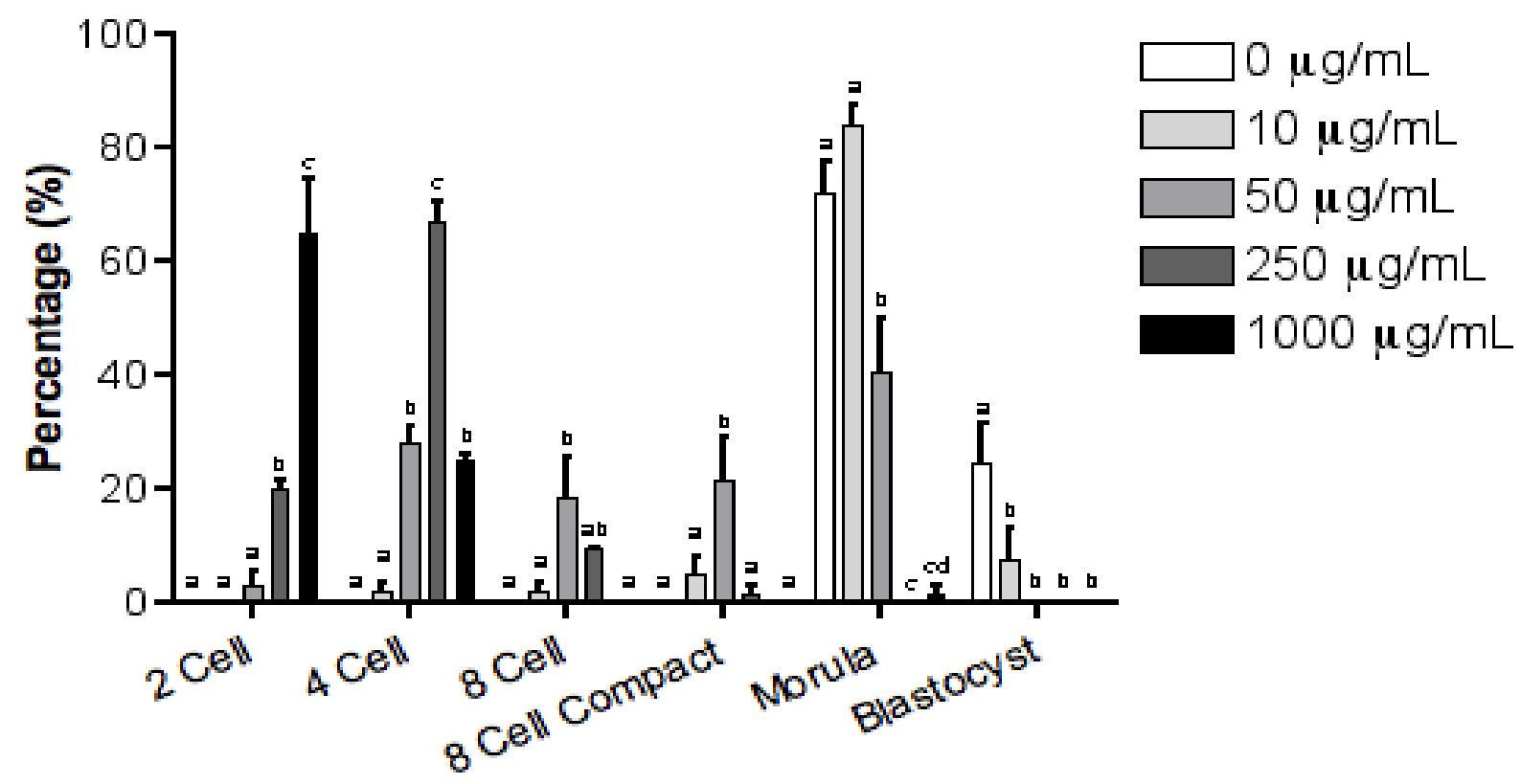

Embryonic Stage

B $72 \mathrm{~h}$ recovery after treatment with aqueous extract

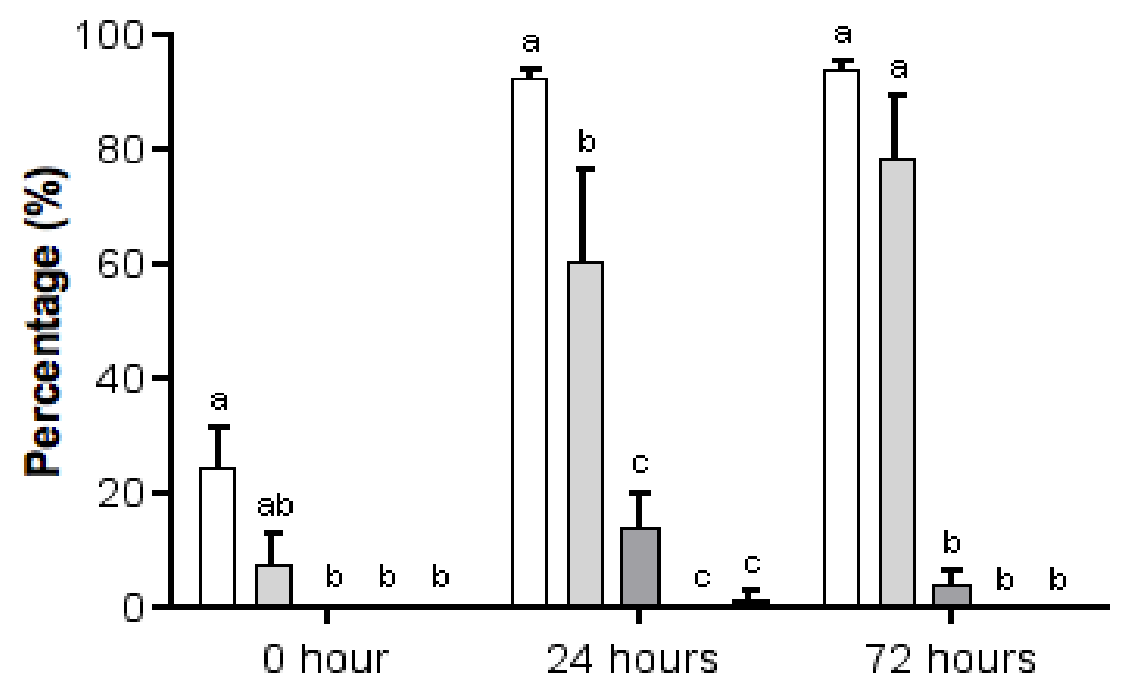

Blastocyst Development 
Figure 2

A $48 \mathrm{~h}$ treatment with alcoholic extract

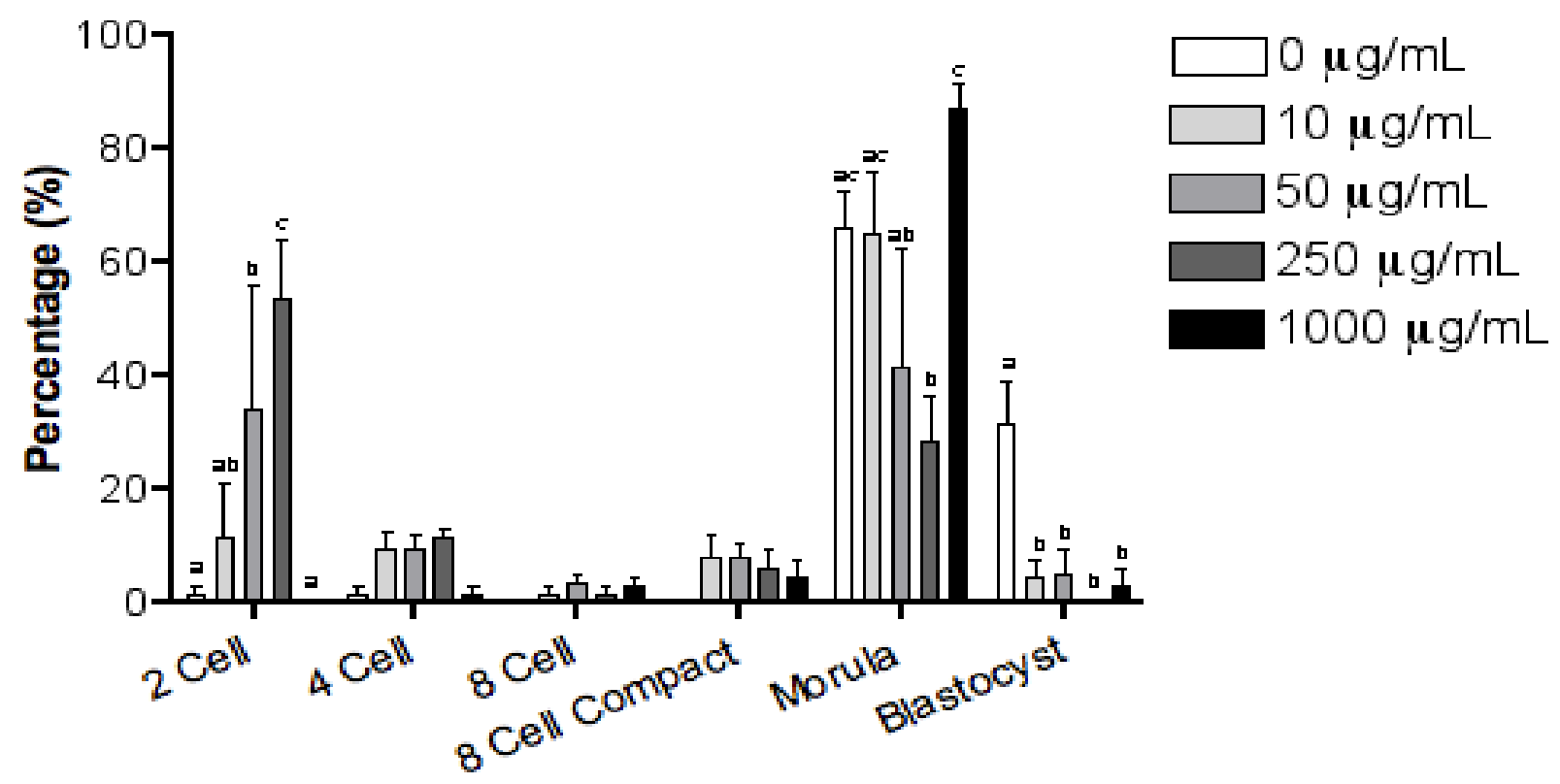

Embryonic Stage

B $72 \mathrm{~h}$ recovery after treatment with alcoholic extract

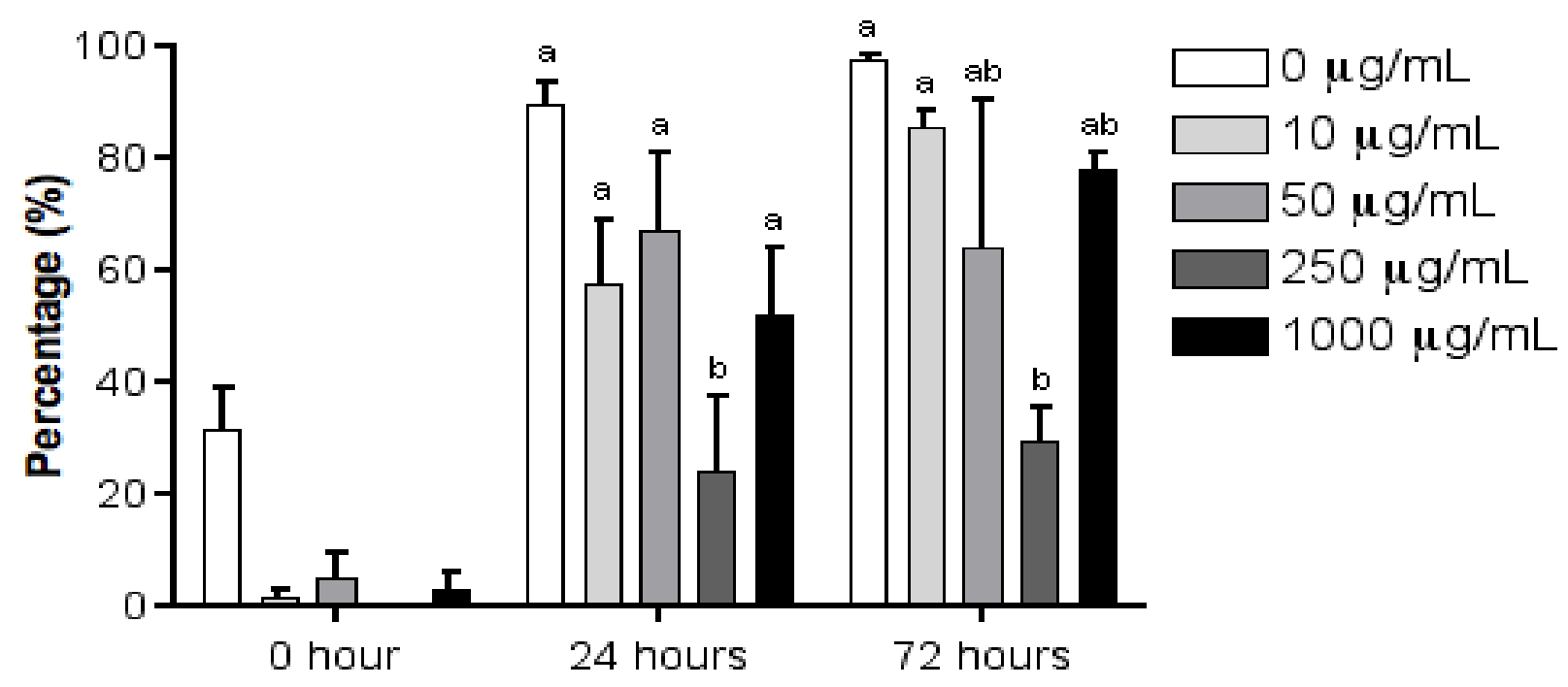

Blastocyst Development 
Figure 3

A $\quad 48 \mathrm{~h}$ treatment with $\mathrm{Rb} 1$

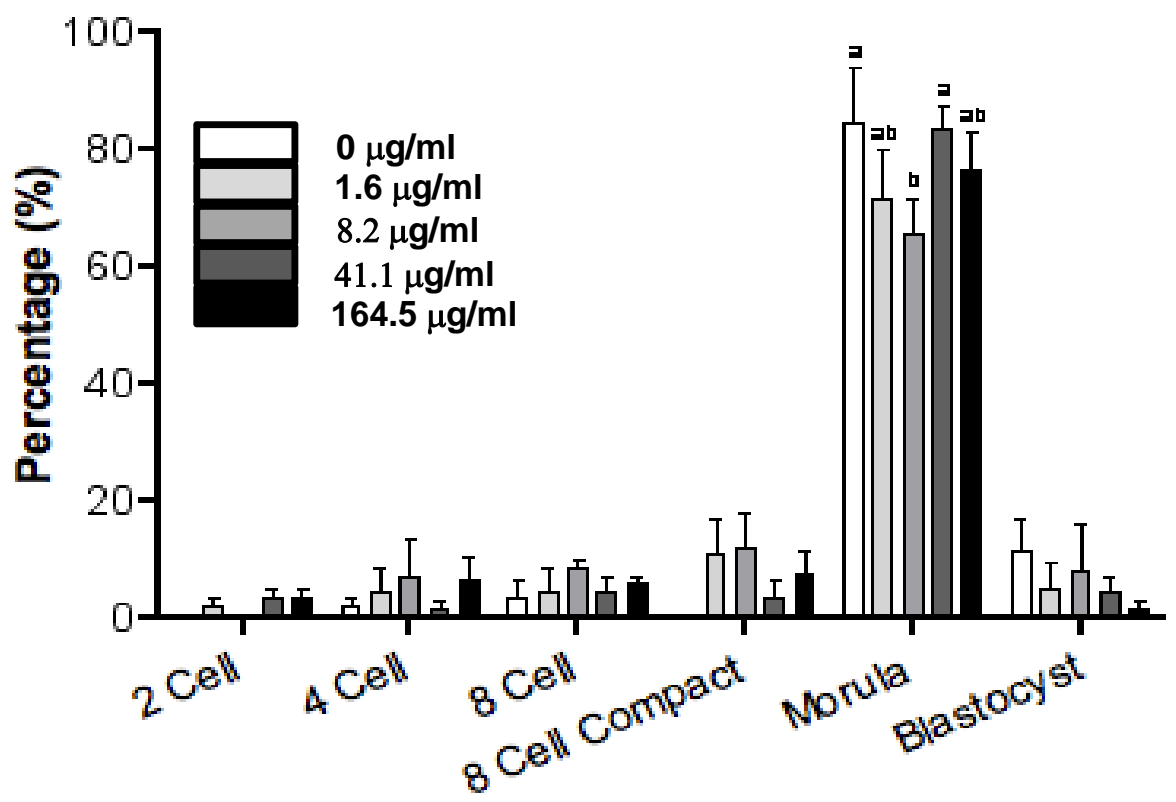

Embryonic Stage

B $\quad 72 \mathrm{~h}$ recovery after treatment with $\mathrm{Rb} 1$

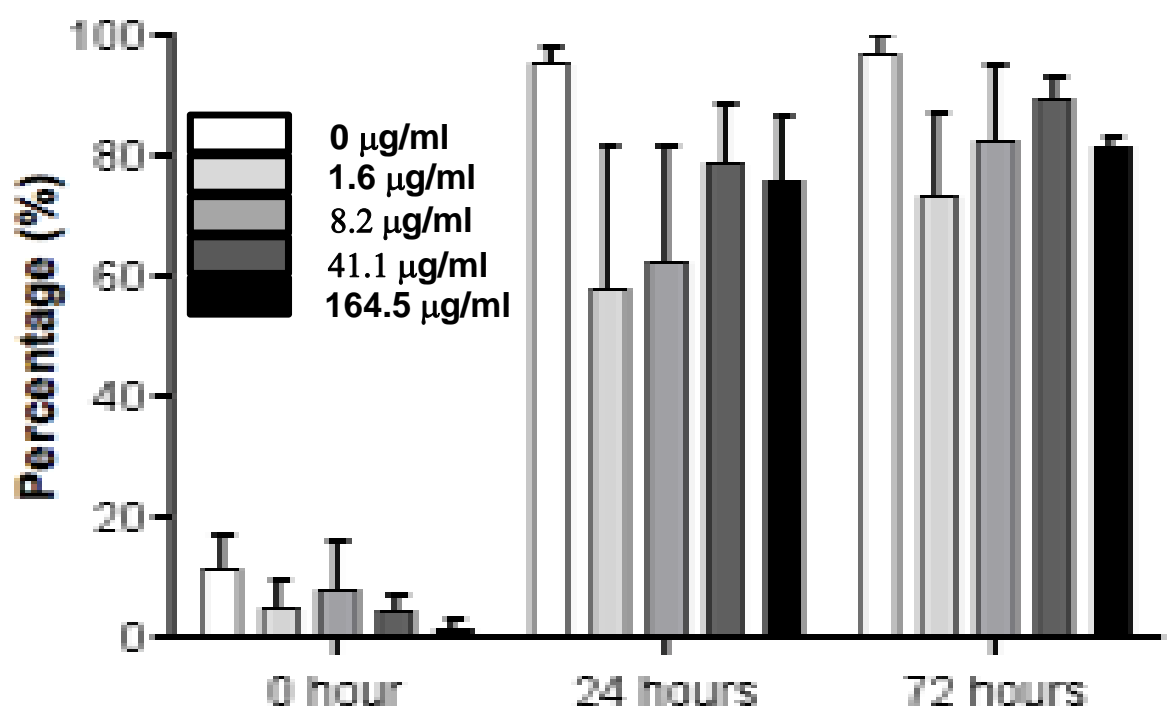

Blastocyst Development 
Figure 4

A $48 \mathrm{~h}$ treatment with Rg1

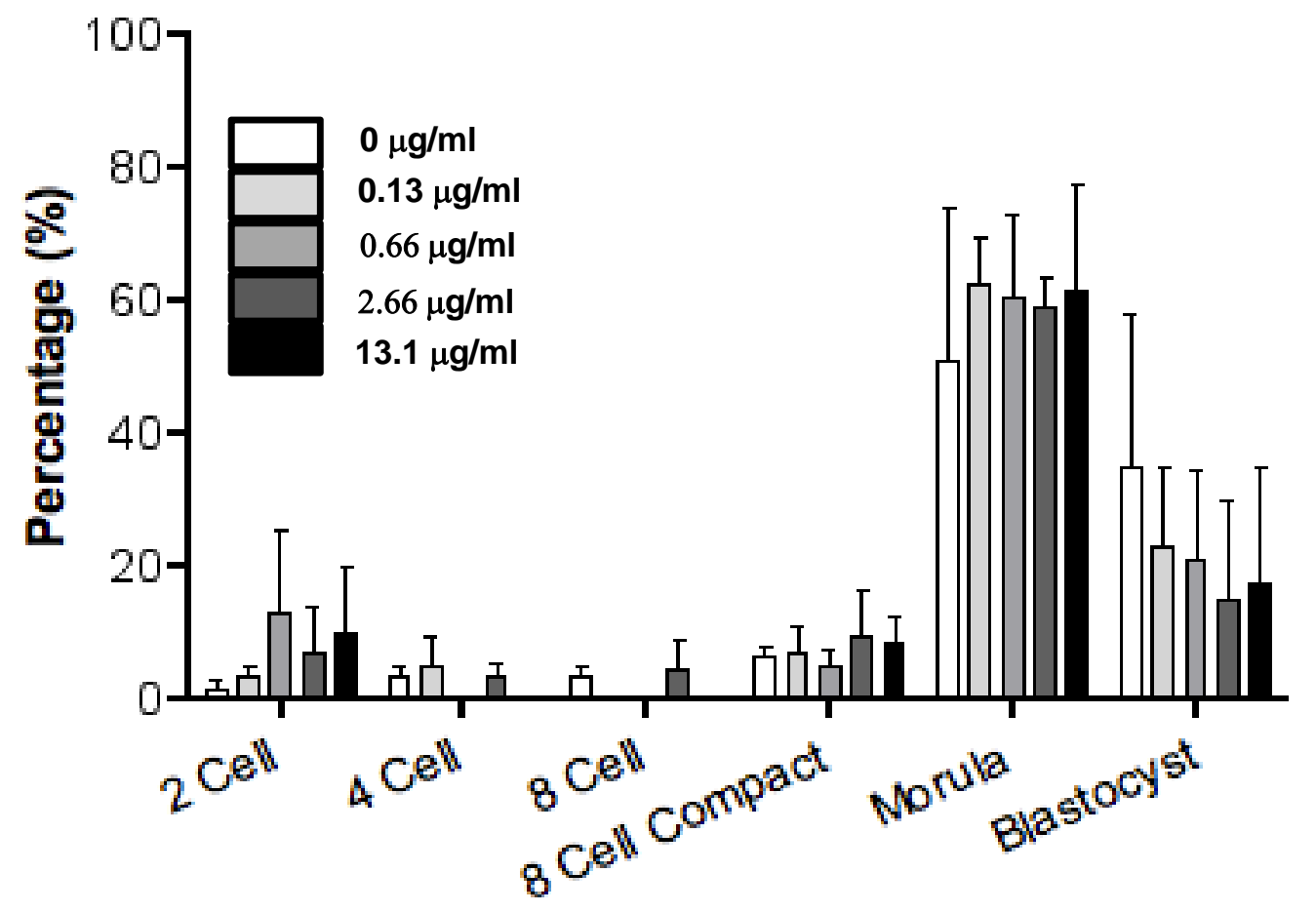

Embryonic Stage

B $72 \mathrm{~h}$ recovery after treatment with $\mathrm{Rg} 1$

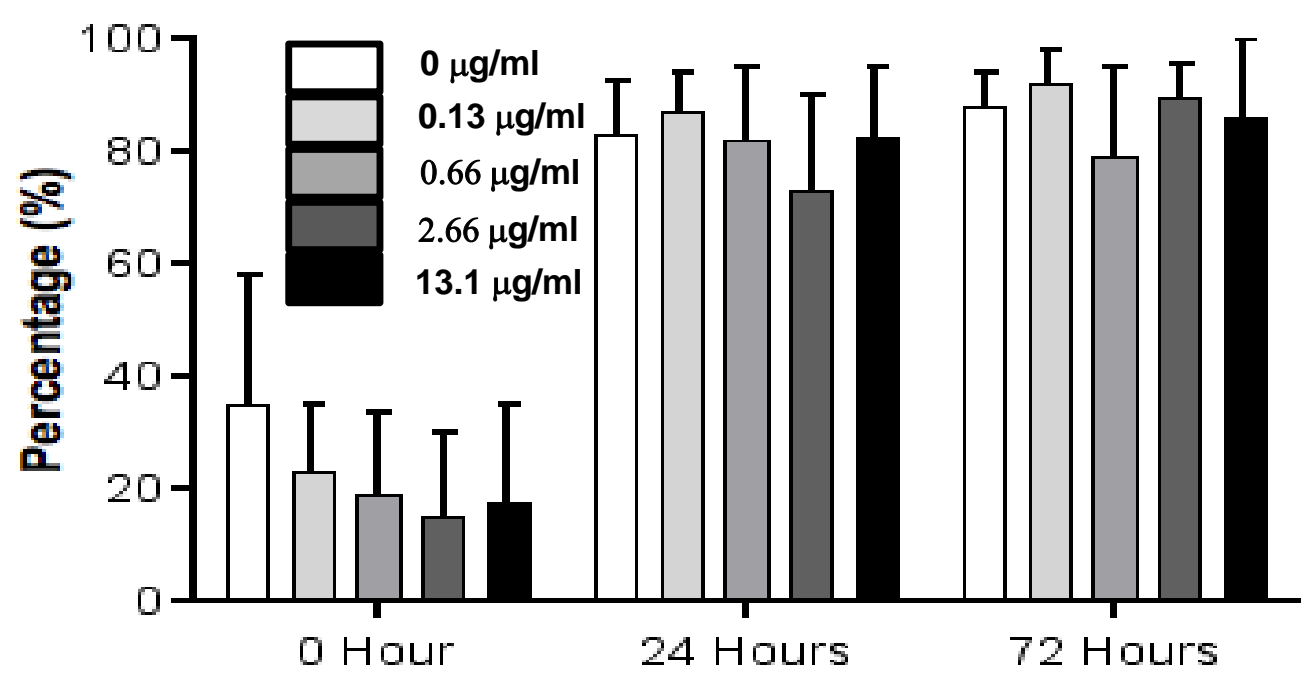

Blastocyst Development 
Figure 5
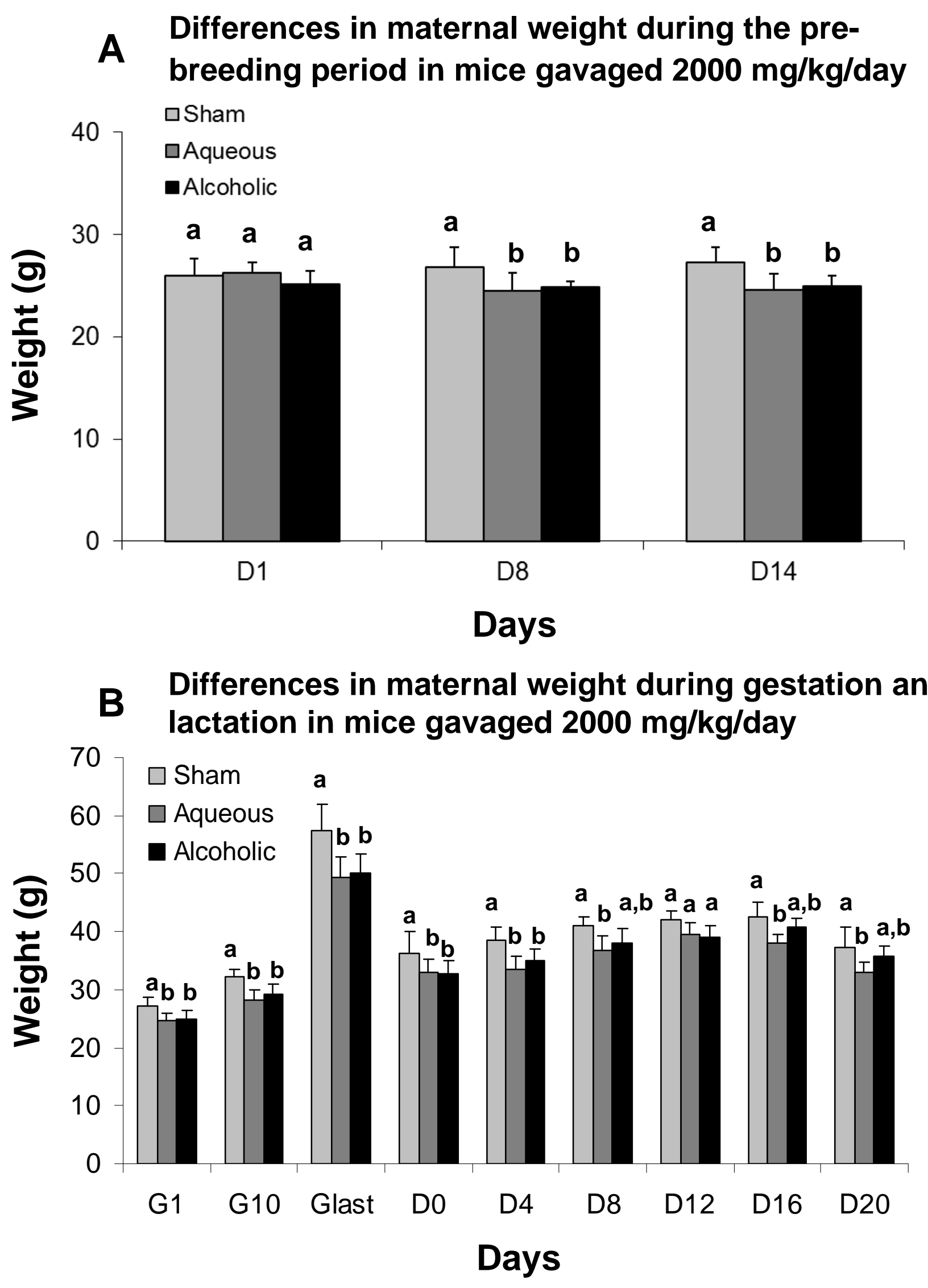